\title{
Oligoastrocytoma, Not Otherwise Specified
}

National Cancer Institute

\section{Source}

National Cancer Institute. Oligoastrocytoma, Not Otherwise Specified. NCI Thesaurus.

Code C129323.

A diffuse glioma characterized by the presence of both an astrocytic and an

oligodendrog lial component and the absence of information on the IDH genes status. 